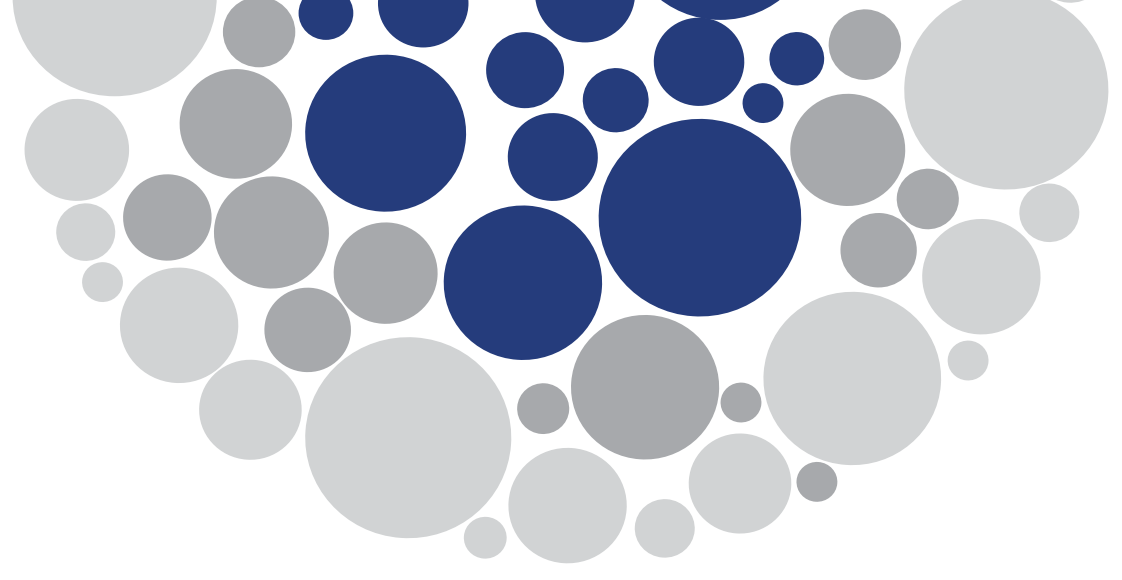

\title{
Dom Antônio Salvini (1892-1968): resgate de memória de atuação do padre italiano de Piancastagnaio (Toscana) na Baixada Campista
}

\author{
Elaine Guimarães Godinho' ${ }^{1}$, Edimilson Antônio Mota² \\ ${ }^{1}$ Mestranda no Programa de Pós-Graduação em Geografia PPG - NEPECGIM, Universidade Federal Fluminense (UFF), \\ Campos dos Goytacazes (RJ), Brasil. E-mail: elaineggodinho@gmail.com \\ 2 Prof. da Licenciatura em Geografia e do PPG UFF Campos. Coordenador do Núcleo de Ensino e Pesquisa sobre Espaço e \\ Currículo de Geografia e Imagem e Multiculturalismo - NEPECGIM. E-mail: uffmota@gmail.com
}

O presente estudo objetiva apresentar a influência da cultura italiana no espaço urbano de Campos dos Goytacazes por meio de atividades exercidas pelo imigrante italiano Silvio Salvini, originário da comuna de Piancastagnaio, na região da Toscana.

Neste trabalho, o recorte específico apresenta episódios de parte da vida e obra monástica de Dom Antônio Salvini, conhecido hoje apenas pela geração de terceira idade como Dom Antônio, evidenciando sua atuação e descrevendo curiosidades sobre o episódio da morte do monge.

O município de Campos dos Goytacazes, localizado no Norte Fluminense (mapa 1), é o maior em extensão territorial fora da Região Metropolitana do Estado do Rio de Janeiro, com $4.032 \mathrm{~km}^{2}$, e conta com uma população estimada em 507.548 pessoas, das quais cerca de 90\% estão concentradas na área urbana, e 10\%, na área rural, de acordo com o IBGE (INSTITUTO BRASILEIRO DE GEOGRAFIA E ESTATÍSTICA, 2019).

Grande parte da população hoje é formada por descendentes de africanos, os quais nos séculos passados foram escravizados - nessa mesma época, subexistiam outras colônias estrangeiras, como as de ingleses, franceses, alemães, italianos e austríacos (SOUSA, 2014, p. 142-146). A presença da cultura italiana em Campos dos Goytacazes conta com 


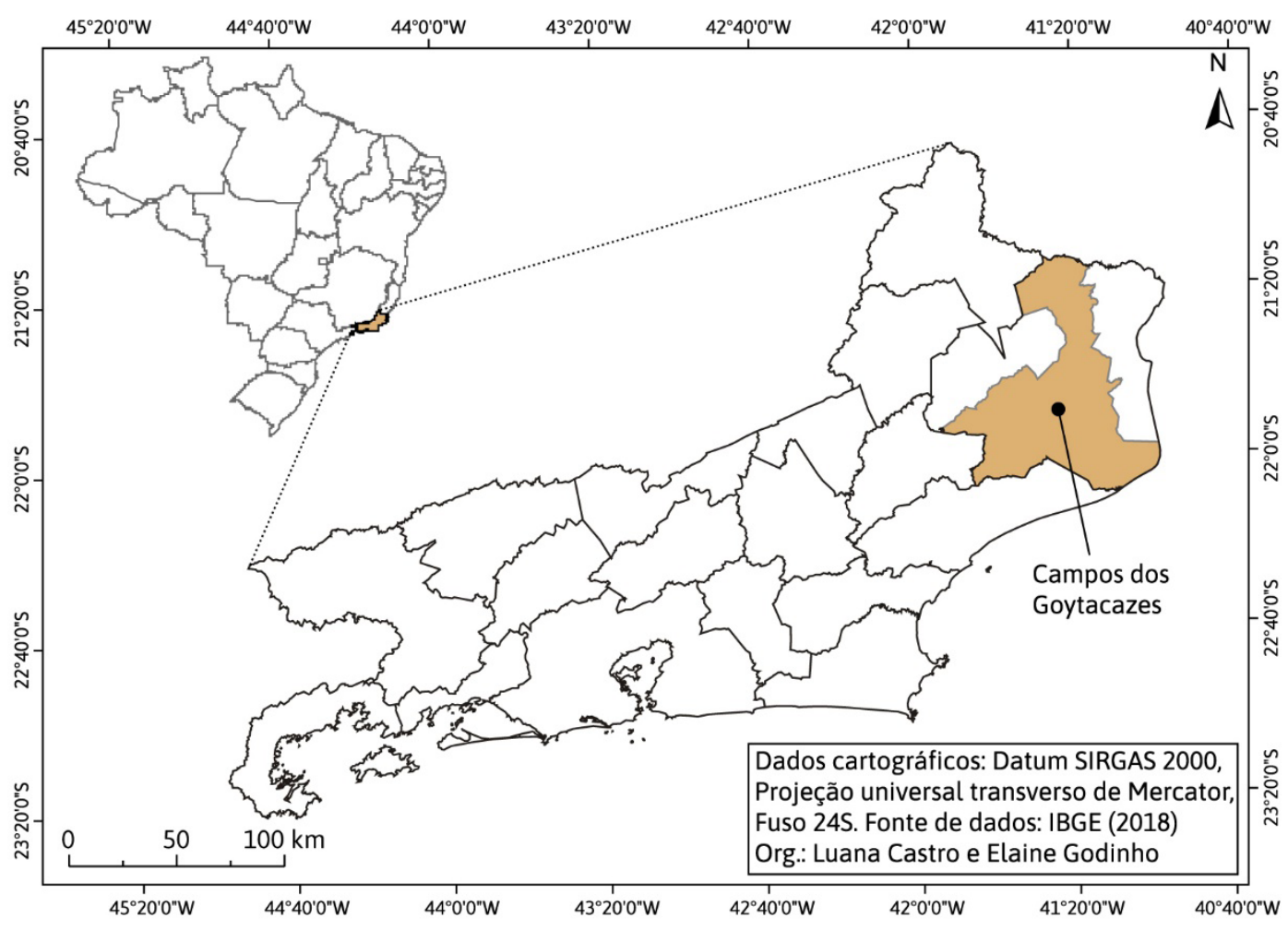

Mapa 1 - Campos dos Goytacazes (CASTRO; GODINHO, 2021a).

marcas temporais postas pelos imigrantes que vieram para a região na esperança de fazer do lugar a segunda terra fora da Itália. Neste sentido, o presente trabalho se propôs a investigar a italianidade no espaço geográfico de Campos dos Goytacazes, evidenciando o legado arquitetônico italiano por meio de prédios públicos, moradias e monumentos presentes na cidade. E, a partir deste arranjo espacial, ficaram evidentes outras atividades decorrentes desses estrangeiros e seus descendentes, como desempenhos políticos, literários, sociais e comerciais, que se desenvolveram no período da Grande Emigração Italiana para o Brasil (1861-1948).

A partir desse contexto histórico, marcas remanescentes de italianidade na paisagem levaram ao desenvolvimento desta pesquisa sobre a atuação dessa rica cultura na história da cidade, a qual precisa ser resgatada e trazida ao conhecimento dos campistas. O conceito de italianidade, por ser amplo, não é autoevidente, visto que implica termos antropológicos (aspectos que envolvem a etnicidade) e sociológicos (aspectos que envolvem construções sociais). Além disso, trata-se de um conceito externo, ou seja, de acordo com Barth (1998, p. 144), um "fenômeno particularmente visível nas situações migratórias em que autóctones têm geralmente tendência a englobar uma identificação comum, frequentemente com base num traço pejorativo (raça), os grupos recém-chegados que se percebem diferenciados". Ainda segundo esse autor, "Lopreato (1970) observa que os migrantes não deixavam a Itália como italianos, mas como genoveses, venezianos, napolitanos, sicilianos, calabreses, etc., e continuavam a identificar-se assim durante longo tempo, senão pelo resto de suas vidas" (BARTH 1998, p. 145). Portanto, a abordagem da italianidade no espaço geográfico de Campos dos Goytacazes refletirá, em termos 
gerais, aspectos múltiplos da cultura italiana para a contribuição histórica, econômica e cultural na formação da cidade.

Notas e relatos presentes no jornal Monitor Campista, no período da Grande Emigração ${ }^{1}$, permitiram evidenciar discursos que denotam o estereótipo da cultura do imigrante. Payer (1999, p. 112), ao discorrer sobre o lugar do sujeito no caso do imigrante italiano, defende que:

[...] é denso simbolicamente o processo de constituição do imigrante como sujeito nacional brasileiro, baseado, como apontamos, em um silenciamento que levou à ausência de formulações histórico-discursivas que contemplassem o real da imigração, para além dos estereótipos. Uma vez tendo havido na história a sub-partição mencionada dos valores relacionados à autoridade, à língua, ao lugar do sujeito, parece-nos que ela encontra-se ainda presente em valores incorporados na rede das filiações históricas nesse campo.

Assim, embora a influência italiana na cidade esteja presente, principalmente, na zona urbana, onde se evidencia um número maior de objetos que se relacionam com a italianidade, na área rural, como a Baixada Campista, ela também se fez presente em atividades relacionadas aos imigrantes por meio do simbólico. Sobre esse tipo de atuação, ou seja, o simbólico no espaço, Rosendahl (2018, p. 57) diz que: "As atividades religiosas imprimem no espaço transformações que estão fortemente relacionadas com os aspectos culturais da comunidade, de tal modo que o espaço pode ser percebido de acordo com os valores simbólicos ali representados".

Ao evidenciar o simbólico na presença da cultura italiana em Campos, são considerados estudos de autores que abordam a emigração italiana para o Brasil, como Emílio Franzina, e também o legado histórico, social e geográfico deixado por estudiosos que referenciam o Norte Fluminense, como Alberto Lamego. Referindo-se à cidade e à imigração estrangeira, em relação à formação étnica, na obra O homem e o Brejo, Lamego (1974, p. 118) escreveu:

A parte essencial da história de penetração da terra foi contada, com a dispersão do homem sobre a gleba. E, ademais, etnicamente esse mesmo homem já está quase feito. O índio sumiu-se no túmulo ou no sangue do colono. O negro continua a misturar-se. Mas o imigrante será sempre o português. Nenhum outro povo contribuiu sensivelmente para a atual etnia campista.

Ao registrar o trecho "Mas o imigrante será sempre o português", Lamego entende que os indígenas foram dizimados, os negros, miscigenados, e o imigrante português seria o único, de fato, a contribuir para a formação étnica do campista, enquanto outros imigrantes, como os italianos, ficariam no esquecimento, segundo seu alcance de visão regional. Sobre esse "esquecimento", Orlandi (2007) lembra que o silenciar pode ser categorizado. Segundo a autora,

[...] em muitas propostas de classificação, domina a concepção negativa do silêncio. Lyotard (1983, p. 30) propõe a distinção de quatro silêncios. Segundo ele, a frase que

\footnotetext{
${ }^{1}$ De acordo com Franzina (2015, p. 36), a emigração apresenta momentos distintos: as origens do fluxo migratório (1861-1875); a primeira fase da imigração italiana (1876-1886); o êxodo dos campos e a imigração permanente de massa nos anos da disputa colonial (1887-1901); a emigração do Sul da Itália para os Estados Unidos e a conclusão do primeiro grande ciclo migratório (1902-1927); as medidas restritivas dos anos 20 ao segundo pós-guerra (1927-1948).
} 
substitui o silêncio seria uma negativa. O que é negado por ela seria uma das quatro instâncias que constituem o universo de frases: o destinatário, o referente, o sentido, o emissor. Ainda segundo esse mesmo autor, a frase implicada pelo silêncio seria uma negativa que se formularia assim: esse caso não é da sua conta; esse caso não existe; esse caso não é significável; esse caso não é da minha conta. Essas categorizações, embora definidas negativamente, trazem alguma contribuição para a compreensão do silêncio e organizam o seu modo de significar. (ORLANDI, 2007, p. 34-35).

Além disso, ainda de acordo com a autora, "as palavras falam com outras palavras. Toda palavra é sempre parte de um discurso. E todo discurso se delineia na relação com os outros: dizeres presentes e dizeres que se alojam na memória" (ORLANDI, 2020, p. 41).

Mas não foram apenas os excertos de Lamego que se re-produziram criando campos discursivos hegemônicos para a aceitação desse enunciado como fato. Antes disso, havia forte atuação de uma aristocracia agrária e escravocrata que queria preservar esse status $q u o$, mantendo seus lucros e privilégios. Por outro lado, essa mesma classe intensificou a importância econômica de Campos, dando à cidade, no final do século XIX e início do XX, fama e modernidade no interior do estado, tendo sido uma dos municípios economicamente mais importantes do período. Entre outras inovações, Campos foi a primeira cidade a implantar luz elétrica no país. ${ }^{2}$

Ao abordar a ideia de região, Bourdieu (1972, p. 116) aponta o discurso regionalista como aquele "que tem em vista impor como legítima uma nova definição de fronteiras e dar a conhecer e fazer reconhecer a região assim delimitada", ou seja, "o ato de enunciar é proporcional à autoridade daquele que anuncia", reforçando ainda mais o reconhecimento do grupo minoritário dominante e afastando a identidade dos outros que se quis/quer longe.

Quanto a esses afastamentos, isto é, esse "silenciamento" dos imigrantes não portugueses em Campos, como os africanos e os italianos, seus elementos linguísticos, culturais e simbólicos são lugares para se conhecer e resgatar como parte da formação regional campista, e, para isso, a memória como lugar de construção e reconstrução social apresenta muitas possibilidades.

Desse modo, trazer a memória das atividades clericais de Salvini é também resgatar parte da atuação silenciada da italianidade em Campos. Assim, este texto está subdividido da seguinte forma: em um primeiro momento, é feita uma breve história acerca da origem, percurso no Brasil e formação do religioso; em um segundo momento, são apresentados o trajeto e a história ao longo de alguns episódios históricos rememorados por moradores da Baixada Campista que conviveram com o monge; por fim, são apresentadas as considerações finais.

\section{Silvio Salvini: origem e destino}

Silvio Salvini nasceu em 1892, na comuna de Piancastagnaio, uma pequena cidade medieval localizada na região da Toscana, ao sul de Siena (mapa 2).

De acordo com informações históricas da Associazione Turistica ProLoco di Piancastagnaio, os manuscritos de Giovanni Antonio Pecci (1693-1768), da segunda metade do século XVII, descrevem a geografia local como situada: "[...] na costa oriental do Monte Amiata, na encosta onde termina uma pequena planície, que se desprende

\footnotetext{
2 A Sultana do Paraíba (ALVES, 2009).
} 


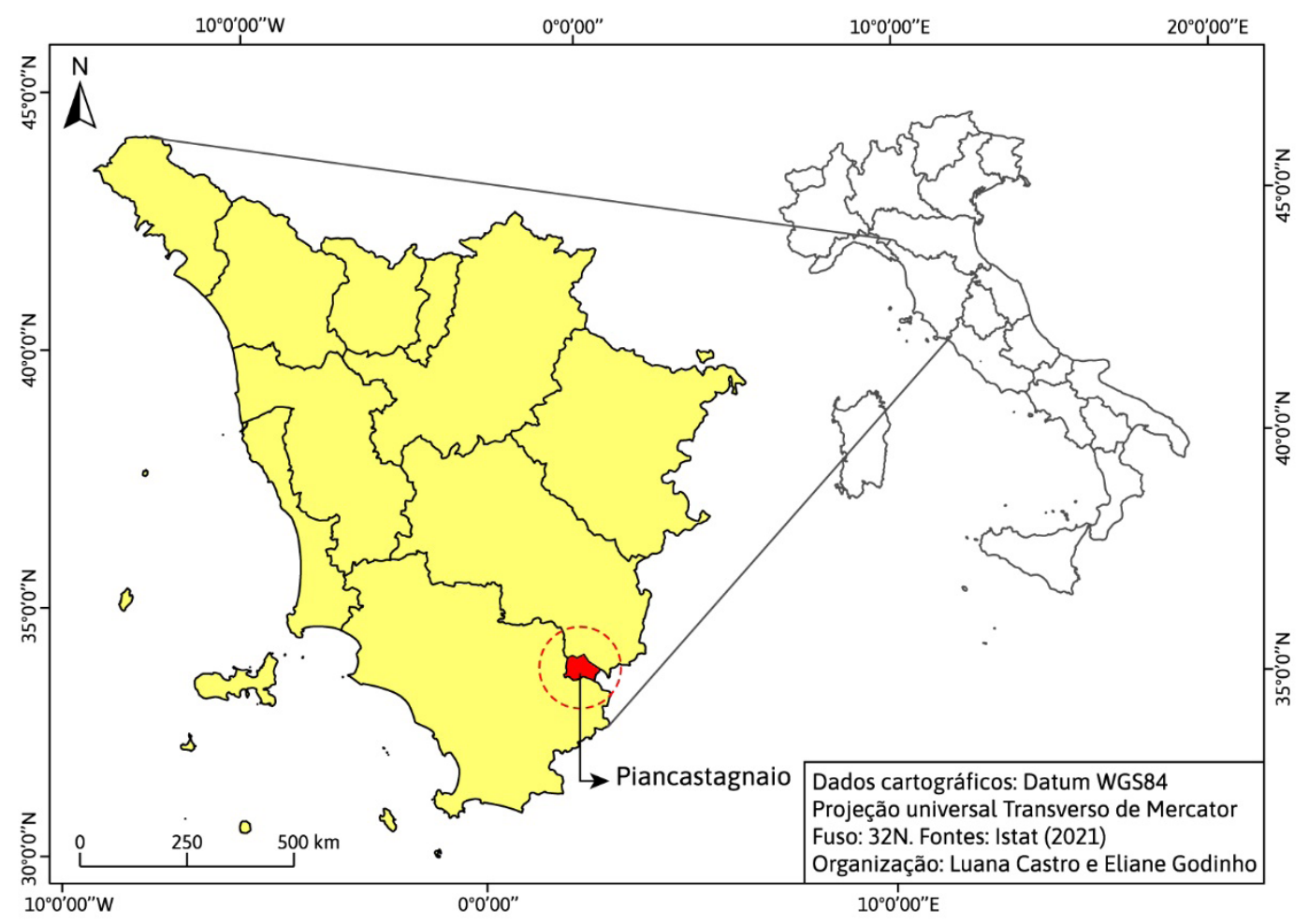

Mapa 2 - Toscana: comuna de Piancastagnaio em destaque circular (CASTRO; GODINHO, 2021b).

da última curva da montanha e através da qual sobe um topo da mesma, um planalto cultivado por belos castanheiros, cujas sombras são agradáveis para passeios no verão" (tradução nossa). ${ }^{3}$

Não foram encontrados registros escolares digitalizados de Salvini nos dados disponíveis consultados da Hemeroteca de Piancastagnaio, por isso ainda pouco se sabe sobre a história de sua infância na comuna e seus registros civis, mas, de acordo com a documentação cedida pelo Mosteiro de São Bento, no Rio de Janeiro, Silvio Salvini era o verdadeiro nome de "Dom Antônio" - como era conhecido pela Baixada Campista.

Sua formação clerical se deu no Rio de Janeiro em 1922, como é possível atestar na Figura 1.

Como é possível perceber na Figura 1, a trajetória curricular de Dom Antônio Salvini comprova sua excelência no curso de Teologia, do Mosteiro de São Bento, Rio de Janeiro, sendo aferida como "magna cum laude".

Depois, ele atuou oficialmente como superior da Casa da Tijuca, no Rio de Janeiro, de 1939 a 1964, e como superior da Casa da Fazenda de São Bento, de Campos, até 1968, quando morreu. Porém, a partir dos anos de 1940, são encontrados registros de suas atuações nos livros paroquiais de Baixa Grande em batismos e matrimônios pela região de Mussurepe. Além disso, depoentes afirmam que o monge chegou à Baixada Campista na década de 1940 .

3 "E' situata la terra di Piano-Castagnaio nella costa orientale del Monte Amiata, sul declive appunto, o scesa, ove termina una piccola pianura, che si stacca dall'ultimo giro di detto Monte, e per il quale alla cima del medesimo si ascende, pianoro coltivato con bellissimi castagni, lombra dei quali, nel calore estivo, serve a un grato e delizioso passeggio." (PROLOCO PIANCASTAGNAIO, 2020). 


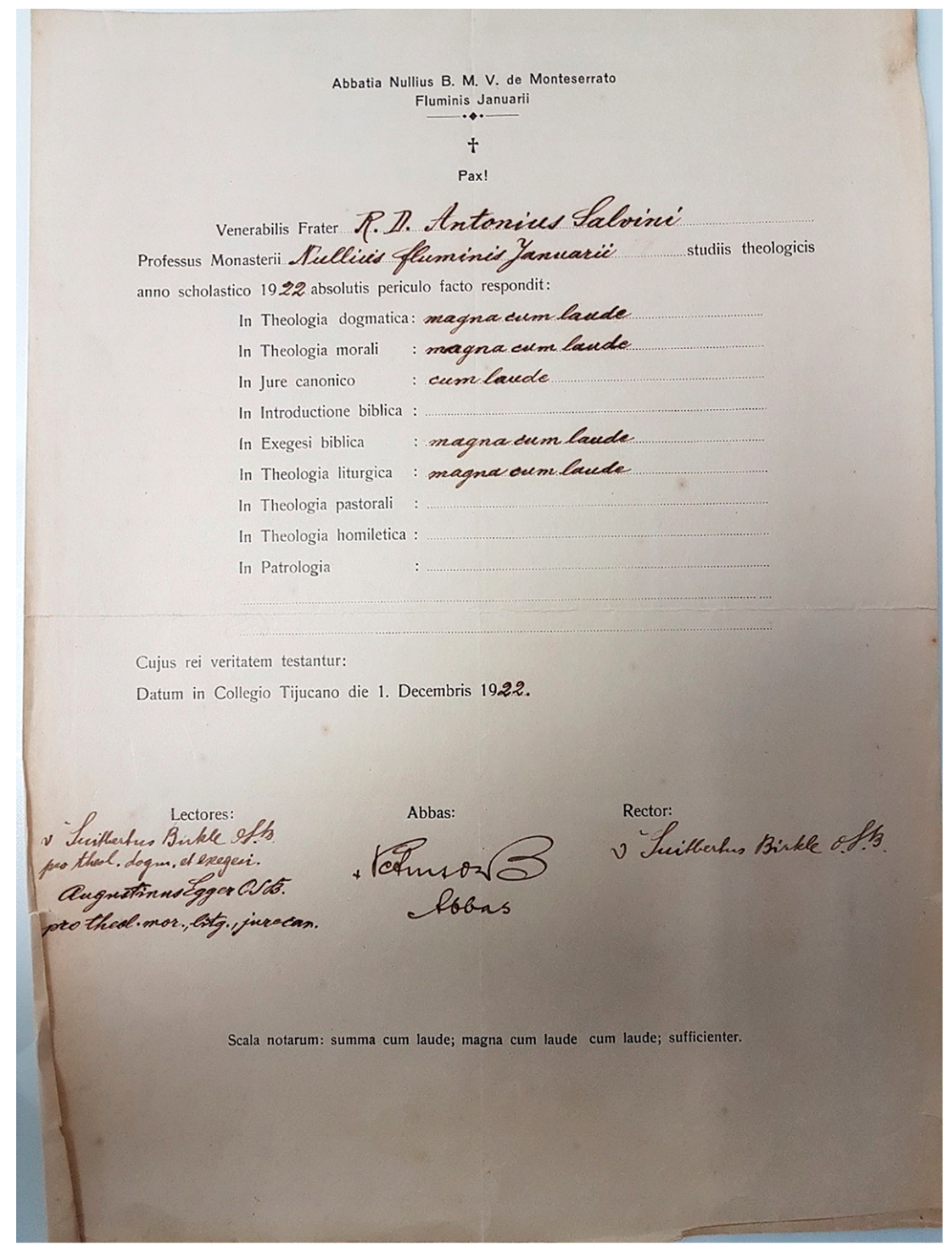

Figura 1 - Histórico de formação acadêmica de Dom Antônio Salvini.

Fonte: Mosteiro de São Bento, Rio de Janeiro. Acesso: 11 set. 2020.

\section{Silvio Salvini: atuação na Baixada Campista}

Ao examinar os livros de registro de sacramentos da Ordem Beneditina de Campos, do período de 1938 a 1950, que correspondem aos números de 1 a 4, disponibilizados pela Arquidiocese de Baixa Grande, a atuação de Dom Antônio Salvini se deu a partir de 1940 em toda a região administrada pela Ordem, realizando batismos e matrimônios. 
Como professor, ele percorria toda a região, atendendo a 32 escolas das comunidades locais, não apenas na Baixada Campista, mas também em algumas localidades de São João da Barra (SJB), sempre se deslocando de bicicleta e a cavalo.

Segundo as informações de Gerson Amaro Ribeiro, 77 anos, ex-aluno do monge, nascido em Cazumbá, e que realiza serviços ao Mosteiro desde jovem, são diversos os locais onde o sacerdote prestava assistência, conforme o Quadro 1.

De acordo com o Quadro 1, a abrangência do trajeto demonstra o quantitativo expressivo de comunidades assistidas pelo sacerdote no ensino da catequese, na celebração de missas e na prestação de assistência social.

Em relato cedido por Gerson, Dom Antônio Salvini foi um padre muito humilde, atencioso, exímio em trabalhos sociais, admirado por todos os fiéis e prestador de muitos serviços à comunidade. Como já mencionado, percorria toda a Baixada Campista de

Quadro 1 - Localidades de atuação sacerdotal de Dom Antônio Salvini.

\begin{tabular}{|c|c|c|c|}
\hline Cidade & $\begin{array}{l}\text { Localidade } \\
\text { (Distrito) }\end{array}$ & Instituição & Endereço/localização \\
\hline Campos & Mussurepe & Mosteiro de São Bento & Estrada Rural, Baixa Grande \\
\hline Campos & Mussurepe & Capela da Pitangueira & Baixa Grande \\
\hline Campos & Mussurepe & Igreja São José (Capela) & Córrego Fundo \\
\hline Campos & Mussurepe & Igreja Nossa Senhora Aparecida & Azeitona \\
\hline Campos & Mussurepe & Colégio de São Bento & Baixa Grande \\
\hline Campos & Mussurepe & Capela & Marrecas \\
\hline Campos & Mussurepe & Igreja de Santo Amaro & Xexé \\
\hline Campos & Sto. Amaro & Capela & Boa Vista \\
\hline Campos & Sto. Amaro & Capela & Caboio \\
\hline Campos & Sto. Amaro & Capela & Correnteza \\
\hline Campos & Sto. Amaro & Capela & Canto do Engenho \\
\hline Campos & Sto. Amaro & Santuário de São Martins & São Martins \\
\hline Campos & Sto. Amaro & Capela de Santo Amaro & Tocos \\
\hline Campos & Farol & Igreja N. S das Rosas & Av. Olavo Saldanha, s/n \\
\hline Campos & Farol & Capela & Vila do Sol \\
\hline SJB & Barra de Jacaré & Capela & Barra de Jacaré \\
\hline SJB & Açú & Capela de São Pedro & Açú \\
\hline SJB & Grussaí & Igreja de Sto. Amaro & Av. Liberdade, 987 \\
\hline SJB & Quixabá & Igreja de São Pedro & Chatuba \\
\hline SJB & Campo de Areia & Capela & Campo de Areia \\
\hline SJB & Águas Pretas & Colégio Coelho da Silva & Águas Pretas \\
\hline SJB & Sabonete & Igreja N.S. Conceição & Sabonete \\
\hline SJB & Farol & Igreja N.S. Navegantes & Farol \\
\hline SJB & Farol & Igreja N.S. Perpétuo Socorro & Boa Vista \\
\hline SJB & Farol & Igreja São Tomé do Farol & Farol \\
\hline Campos & São Sebastião & $\begin{array}{l}\text { Igreja Matriz de São Sebastião (ia apenas } \\
\text { quando convidado) }\end{array}$ & São Sebastião \\
\hline
\end{tabular}


bicicleta ou a cavalo. "A bicicleta era italiana, ele trouxe da terra dele; mais tarde ele teve uma lambreta, uma motinha, e só depois, nos anos 60, é que o abade comprou um fusca vermelho, que de vez em quando ele usava. Mas o carro era da Ordem", disse Gerson.

A assistência a lugares remotos da Baixada Campista reflete a importância da aptidão vocacional de Salvini para tratar esses espaços territoriais, visto que sua presença marca o poder da Ordem que estava sob o seu controle. Mas essa relação se dá em uma estrutura nem sempre polivocal, uma vez que seu papel vocacional humanista está intimamente relacionado ao papel político da Igreja Católica de atuação nesses espaços; portanto, envolve aspectos como religião, território e territorialidade. Ao abordar o conceito de espaço e religião, Rosendahl (2002, p. 59) diz sobre essa tríade:

Os espaços apropriados efetiva ou afetivamente são denominados territórios. Territorialidade, por sua vez, significa o conjunto de práticas desenvolvido por instituições ou grupos, no sentido de controlar um dado território. É nesta poderosa estratégia geográfica de controle de pessoas e coisas, ampliando muitas vezes o controle sobre espaços, que a religião se estrutura, enquanto instituição, criando territórios seus.

Como bem coloca a autora, a apropriação do território tem a ver com o conjunto de práticas cujo sentido é controlar pessoas e coisas. O entrevistado Chichico (2020) não tece críticas a respeito da memória de Dom Salvini: "Ninguém tinha nada para falar desse padre. Era muito bondoso, ajudava muito as pessoas, toda vida ele foi assim. Ninguém nunca falou nada dele, teve uma vida exemplar, era muito humilde, parava e conversava muito com as pessoas, conhecia todo mundo". De fato, essa é a verdade de Chichico. A memória não o traiu a respeito do monge, e sua admiração é fruto da convivência diária com Dom Antônio Salvini. Porém, ao analisar as atividades laborais do monge apenas como parte do cumprimento da sua função na Ordem religiosa, não estaria Dom Salvini apenas exercendo com eficiência o papel de catequizador, e, para isso, utilizava-se dos instrumentos de controle ao seu alcance para manter as 32 comunidades assistidas sob o seu domínio?

Como foi exposto anteriormente, território significa poder, e este pode estar expresso em formas simbólicas, o que Corrêa (2018) denominou "formas simbólicas espaciais", por estarem diretamente relacionadas ao espaço, constituindo-se em seus fixos e fluxos. Assim,

A relação íntima entre certas formas simbólicas e espaço resulta de uma política locacional das formas simbólicas, derivadas, por sua vez, da intenção delas de cumprirem o mais eficientemente possível o papel delas esperado por aqueles que as conceberam e as produziram. (CORRÊA, 2018, p. 228).

Considerando o Mosteiro de São Bento, em Mussurepe, em Campos dos Goytacazes, como forma simbólica de poder, primeiramente se fixou naquela paisagem rural o prédio da Ordem para desenvolver sua política locacional. Posto isto, seria função cotidiana dos monges usar mecanismos discursivos (doutrina) na assistência aos fiéis e manter o domínio da política local com o uso da fé.

Essa política envolve as dimensões absoluta, relativa e relacional do espaço. Uma forma simbólica espacial tem uma localização absoluta, um sítio, onde ocorreu um evento considerado significativo, ou que é considerado adequado ou eficaz para celebração, contestação ou memorialização, ou ainda porque o local já é dotado de algum atributo simbólico que valorizaria os objetos simbólicos fixos e as paradas, desfiles ou procissões, ampliando a força simbólica deles. (CORRÊA, 2018, p. 228). 
Nesse caso, Dom Salvini, na memória do entrevistado Gerson, torna-se uma pessoa sem contradições e passa a ocupar o lugar do sagrado. Para ele, o trabalho do monge é isento de críticas, como relata:

Dom Antônio foi professor de catecismo a vida toda e fez um trabalho muito bom. Ele percorria 32 escolas na região ensinando religião. Não temia nada, entrava na lama, andava nos alagadiços a cavalo carregando água benta, fazia de tudo pra servir as pessoas. Ele fazia extrema-unção..., quando chamavam ele em qualquer lugar que fosse. Era muito atencioso, por exemplo, se alguém precisasse de uma roupinha, qualquer coisa assim, gente muito pobre né, sem condições, ele dava um jeito de levar pra pessoa. Ele ia até o Açú de bicicleta. Ele percorria Águas Pretas, Sabonete, Córrego Fundo, Marrecas, Barra de Jacaré, toda essa região, e dava aula no Colégio de São Bento e no Grupo de Mussurepe. Servia nas capelas de Boa Vista, Mussurepe, Águas Pretas, Azeitona, São Pedro, São Martins, Canto do Engenho e ajudava na administração do Mosteiro. No dia da morte dele, ele tava indo de bicicleta para o Farol e parece que chamaram ele, coisa assim, ele foi olhar pra trás e nisso que ele virou parece que o carro pegou ele.

De acordo com Corrêa (2018, p. 41), "a memória é seletiva e influenciada por aqueles que observam a paisagem”, pois “a memória tem uma dimensão polivocal”. Assim, acerca da polivocalidade, cada convívio prezará por uma memória particular, e a população de convívio fará também uso da coletiva. Um exemplo de coletividade, neste caso, pode ser citado no episódio da morte do padre. Ainda segundo o relato de Gerson, nessa época a população se reuniu e fez uma carta ao abade superior para que o corpo de Dom Salvini fosse enterrado em Mussurepe, visto que é costume da Ordem conduzir os corpos dos sacerdotes para serem sepultados no cemitério do Mosteiro, no Rio de Janeiro. $\mathrm{O}$ abade concordou com o desejo da comunidade, então o padre Antônio Salvini teve seu sepultamento no cemitério do Mosteiro de São Bento, em Mussurepe.

Atualmente, os restos mortais dele foram exumados por conta da restauração pela qual o mosteiro está passando e estão guardados à espera do término das obras, para que sejam sepultados de acordo com os costumes beneditinos: no altar da igreja.

De acordo com outro depoimento de um morador da região, Francisco de Assis Pessanha da Silva, 75 anos, servidor público aposentado da prefeitura, conhecido em Mussurepe como Seu Chichico:

[...] todo mundo chamava ele de Dom Antônio, ele era português né, tinha um sotaque carregado, mas falava muito bem o português. Ele foi o padre que fez meu casamento. Esse padre andava ou a cavalo ou de bicicleta pela região toda da Baixada, a vida todinha dele foi isso aí, desde que chegou aqui na região. Não tinha tempo ruim pra ele não. Sempre que requisitavam ele, pra qualquer coisa, ele ia, de qualquer jeito. Tinha muita paciência, tava sempre ajudando as pessoas. Muito amoroso. Não era muito alto não, era da minha estatura mais ou menos, não era gordo não, era esbelto... parece até que eu tô vendo ele aqui na frente, lembro muito dele. Ele foi atropelado entre a casa de um irmão meu, Celso Rodrigues da Silva, e a casa de Marcelino, que ficava do outro lado. Quando ele morreu já tinha idade, ele já morreu na idade de velho já. Olha, quando eu casei, eu tinha 20 anos, e ele já devia ter uns 60, eu acho. Nessa época o padre usava um relógio de bolso, daqueles que tinha uma corrente, sabe como é? Ele guardava no bolso. Ele tinha um carinho com aquele relógio... No dia que ele morreu, o relógio sumiu. Eu acho que eu sei quem roubou o relógio... vou falar procê... Era um homem que eu até trabalhei pra ele quando era jovem. Essa pessoa não tá aqui mais entre nós. Todo mundo dizia que quem roubou o relógio foi o Francisco Sardinha, 
mas a polícia na época não achou nada, então não se pode falar nada, né? Mas todo mundo fala isso. Hoje eu falo porque ele já morreu, né. Ele era puxador de cana e tinha um tratorzinho. Ele tinha umas terrinhas ali na estrada do Jenipapo, mas ninguém nunca pode provar nada, porque ninguém viu, isso é que o povo fala, né? Porque o corpo do padre ficou caído na estrada umas três horas até buscarem ele... Mas todo mundo adorava Dom Antônio. Esse foi um padre que chegou e todo mundo gostou dele. Era de uma linha tão fina, que nunca ninguém abriu a boca pra falar nada dele, porque de outros sempre falavam uma coisinha, né, mas dele não, só falavam bem, até hoje falam bem dele.

Ainda sobre a morte de Dom Antônio, Gerson Ribeiro, o primeiro entrevistado, confirmou o relato de Francisco. Ambos afirmaram o local da morte, o episódio do atropelamento, cujo veículo até hoje não se sabe se fora identificado, o desequilíbrio da bicicleta e o fato de duas pessoas, entre as quais o agricultor Francisco Sardinha, terem sido os únicos responsáveis por guardar o corpo até a chegada do socorro, que na época demorou cerca de três horas para recolhê-lo.

Acerca do resgate da memória do episódio da morte, sabe-se que as memórias também podem ser inventadas. Sobre a invenção da memória, Corrêa (2018, p. 41) diz que:

A memória, por outro lado, pode ser inventada, e para isso a paisagem desempenha um papel-chave, exibindo cenas que transmitem mensagens sobre um passado que as elites desejam que seja recriado, inventado. As formas simbólicas espaciais constituem o veículo para esta transmissão. Trata-se da paisagem da simulação do passado, que transporta o observador a um passado que não existiu, criando uma memória seletiva e equivocada.

Nos depoimentos colhidos do senhor Gerson e do senhor Chichico, ambos expressam a verdade a respeito da memória do padre Dom Antônio Salvini. Como coloca Corrêa no trecho anterior, a memória pode ser inventada, visto que ela é fruto da imaginação, e, nesse caso, a paisagem rural, o prédio da Ordem e as atividades assistenciais e catequéticas do monge são elementos robustos na criação de uma memória seletiva, equivocada ou não. Assim, a memória do Dom Antônio Salvini não é uma criação equivocada. Além dos depoimentos orais dos entrevistados, a trajetória do monge está documentada desde sua saída da Itália, sua formação e atuação no Mosteiro de São Bento até suas atividades assistenciais no Mosteiro em Mussurepe, na Baixada Campista. Posto isto, foram vistas as possibilidades de, a partir de sua memória, reconstruir a paisagem, o tempo e o espaço da atuação sacerdotal de Silvio Salvini, a começar pela pergunta sobre o porquê da escolha do "heterônimo" "Dom Antônio", ressoando aportuguesamento e se sobrepondo à italianidade no "ortônimo" de "Dom Salvini", mas isso é questão para um outro trabalho.

\section{Conclusão}

Com base em pesquisa nos livros paroquiais disponibilizados pela Arquidiocese em Baixa Grande (Campos dos Goytacazes), em documentação digitalizada cedida pelo Mosteiro de São Bento e em dois relatos acerca do protagonismo do padre Antônio Salvini na Baixada Campista entre os anos de 1940 a 1968, este texto discorreu sobre a atuação e morte do monge italiano a fim de trazer um breve recorte do tempo-espaço da atuação e assistência a 32 comunidades feitas pelo o então Dom Salvini. Abordou a 
importância das formas simbólicas espaciais, um conceito proposto pelo geógrafo Roberto Lobato Corrêa para tratar a ideia de sítio como lugar de acontecimento e de memória polivocal. Para a estratégia geográfica de controle de pessoas e coisas para a ampliação do controle sobre espaços pela religião enquanto instituição, os espaços apropriados efetiva ou afetivamente (territórios) e as práticas desenvolvidas por instituições ou grupos (territorialidade), utilizou-se de conceitos de Zeny Rosendahl. Por fim, o resgate da memória de atuação do padre italiano de Piancastagnaio (Toscana) na Baixada Campista representa a possibilidade de reconstruir, a partir de sua memória e com base nas suas atividades, não somente surajetória, mas também o papel político e social da Ordem do Mosteiro de São Bento na paisagem campista.

\section{Referências}

ALVES, H. M. A Sultana do Paraíba. Reformas urbanas e poder político em Campos dos Goytacazes 1890-1930. Rio de Janeiro: Arquivo Público do Estado do Rio de Janeiro, 2009.

BARTH, F. Grupos étnicos e suas fronteiras. In: POUTIGNAT, P.; STREIFFFENART, J. Teorias da etnicidade. São Paulo, SP: UNESP, 1998.

BOURDIEU, P. O poder simbólico. Rio de Janeiro: Bertrand Brasil, 2007.

CASTRO, L.; GODINHO, E. Mapa de Campos dos Goytacazes. Petrópolis, 2021a. Acervo Pessoal.

CASTRO, L.; GODINHO, E. Mapa da Toscana: comuna de Piancastagnaio. Petrópolis, 2021b. Acervo Pessoal. CORRÊA, R. L. Caminhos paralelos e entrecruzados. São Paulo: EDUSP, 2018.

FRANZINA, E. A grande emigração: o êxodo dos italianos do Vêneto para o Brasil. 2. ed. Campinas: Ed. UNICAMP, 2015.

INSTITUTO BRASILEIRO DE GEOGRAFIA E ESTATÍSTICA - IBGE. Censo populacional 2019. Rio de Janeiro, 2019. Disponível em: <https://www.ibge.gov.br/estatisticas/sociais/populacao/9103-estimativasde-populacao.html? edicao=25272\&t=resultados $>$. Acesso em: 14 jul. 2021.

LAMEGO, A. R. O homem e o brejo. 2. ed. Rio de Janeiro: Lidador, 1974.

ORLANDI, E. P. Análise de discurso. 13a . ed. Campinas: Editora Pontes, 2020.

ORLANDI, E. P. As formas do silêncio no movimento dos sentidos. 6. ed. Campinas: Editora da UNICAMP, 2007.

PAYER, M. O. Memória da Língua. Imigração e Nacionalidade. 1999. 186 f. Tese (Doutorado em Língüística)Universidade Estadual de Campinas, Campinas, 1999. Disponível em: < http://repositorio.unicamp.br/ jspui/bitstream/REPOSIP/270700/1/Payer_MariaOnice_D.pdf>. Acesso em: 19 Ago. 2020.

PROLOCO PIANCASTAGNAIO. La Storia. 2020. Disponível em: <https://www.prolocopiancastagnaio. it/la-storia/>. Acesso em: 11 set. 2020.

ROSENDAHL, Z. Espaço e religião: uma abordagem geográfica. 2. ed. Rio de Janeiro: EDUERJ, 2002.

ROSENDAHL, Z. Uma procissão na Geografia. Rio de Janeiro: EDUERJ, 2018.

SOUSA, H. Cyclo Aureo: História do $1^{\circ}$ Centenário de Campos. Campos dos Goytacazes, RJ: Essentia, 2014. Reedição da obra original de 1935.

\section{SOBRE OS AUTORES}

Elaine Guimarães Godinho. Mestranda no Programa de Pós-Graduação em Geografia PPG - NEPECGIM, Universidade Federal Fluminense (UFF), Campos dos Goytacazes (RJ), Brasil.

Edimilson Antônio Mota. Prof. da Licenciatura em Geografia e do PPG UFF Campos. Coordenador do Núcleo de Ensino e Pesquisa sobre Espaço e Currículo de Geografia e Imagem e Multiculturalismo - NEPECGIM 